\title{
TEORIAS DE CURRÍCULO E CONCEPÇÕES DE LÍNGUA NO ENSINO DE LÍNGUA PORTUGUESA
}

\section{Delane Cristina Galiza Lourenço * Nathalia Niely Tavares Alves de Melo*}

\begin{abstract}
Resumo: Os estudos de currículo perpassam toda a esfera educacional e influenciam de maneira direta o processo de ensino e aprendizagem em todos os níveis de escolaridade e formação. É mediante esse contexto que realizamos a revisão bibliográfica que se segue, objetivando identificar as relações entre as teorias tradicionais, críticas e pós-críticas de currículo e as concepções de língua que nortearam e ainda norteiam o ensino de língua portuguesa enquanto língua materna. Tomamos como base o percurso histórico traçado por Marinho (2007), Macedo (2013) e Moreira (1999; 2010; 2012) e Silva (2017), quanto aos estudos de currículo, correlacionando-o às concepções de língua apresentada por diversos autores: MORATO (2004), CORREA (2003), MARCUSCHI (2008) e outros.
\end{abstract}

Palavras-chave: Teorias de currículo; Concepções de língua; Ensino de língua portuguesa.

Introdução

Na disciplina intitulada "Teorias linguísticas: bases e perspectivas" ${ }^{*}$, parte da grade curricular do Programa de Pós-graduação em Linguagem e Ensino, da Universidade Federal de Campina Grande, objetivou-se a execução de um levantamento bibliográfico que contemplasse as teorias do conhecimento linguístico, bem como, que esta produção estivesse ligada aos grupos de pesquisa nos quais os discentes estivessem inseridos. Desta forma, o trabalho que se segue contempla as concepções de língua que nortearam os estudos em linguística e o ensino de língua portuguesa (TRAVAGLIA,1997) e as teorias de currículo (SILVA, 2017).

Nos últimos anos, os estudos no campo de currículo vêm adquirindo destaque e visibilidade dentro dos estudos que concernem ao âmbito educacional (MOREIRA, 2013), professores, gestores e sobretudo pesquisadores têm tomado esse objeto de estudos enquanto essencial para o desenvolvimento de uma prática de ensino e aprendizagem eficaz. O currículo pode ser conceituado de maneiras diversas, primeiro quanto à sua complexidade, como também, em relação à época da história em que esteja situado. De acordo com Silva (2017), as teorias de currículo se dividem em três tipos: tradicionais, críticas e pós-críticas. Cada uma dessas abordagens, tomavam o currículo sob um ponto de vista e com objetivos específicos, e partimos do pressuposto de que essas teorias

\footnotetext{
*Graduada e pós-graduada em Letras (Língua Portuguesa) pela UFCG. Mestranda no PPG de Linguagem e Ensino - UFCG. E-mail: delanelourenco@hotmail.com

${ }^{*}$ Graduada em Letras (Língua portuguesa) pela UFCG. Mestranda no PPG de Linguagem e Ensino - UFCG. E-mail: Niely.nathaalia@gmail.com

* Sob a orientação da Prof.a Dr. a Maria Augusta Gonçalves de Macedo Reinaldo.
} 
influenciaram o ensino das disciplinas escolares, como a língua portuguesa. Assim, objetivamos aqui delinear as convergências e divergências das teorias de currículo e as concepções de língua que nortearam o ensino nos últimos anos.

A relevância do levantamento aqui apresentado de justifica pela lacuna de conhecimento existente no campo de pesquisa relativo aos estudos de currículo e ensino de língua portuguesa. Em consulta nas plataformas científico-acadêmicas CAPES e SciELO, foram inseridas as palavras-chave "currículo" e "ensino de língua portuguesa", obtendo como resultado, pouco mais que uma dezena de textos publicados nos últimos anos. Contudo, utilizando as palavras-chave "currículo" e "ensino", foram encontrados inúmeros arquivos concernentes a outras disciplinas. Logo, são importantes a pesquisa e a publicação de textos que contemplem os estudos nas áreas de currículo e ensino de língua.

O artigo está dividido em dois tópicos, sendo o primeiro relativo ao levantamento bibliográfico, e é intitulado: As teorias de currículo e as concepções de língua(gem). O tópico citado está subdividido em outros dois, sendo: As concepções de língua como expressão do pensamento e instrumento de comunicação: currículo tradicional e A concepção de língua como interação: currículo crítico e póscrítico. O segundo tópico, concerne às nossas considerações finais, seguidas das referências que nortearam o trabalho.

1. As teorias de currículo e as concepções de língua(gem)

As transformações ocorridas no contexto social, político, econômico, ideológico de um povo implica numa determinada teoria de currículo. Com isso cada pensamento curricular compreende uma determinada seleção de cultura, de relações de poder e de conhecimentos vigentes.

Segundo alguns teóricos (MACEDO, 2013; MOREIRA, 1999/2010; SILVA, 2017), a definição de currículo depende de como ele é concebido pelos diversos autores em diferentes teorias. Assim, esse objeto de investigação precisa ser abordado numa perspectiva histórica, uma vez que passa por um processo de "hibridização" (MOREIRA, 2010), ou seja, em diferentes momentos temos diferentes teorias de currículo.

Conforme mencionado, o currículo associa-se a distintas concepções, que derivam dos diversos modos de como a educação é concebida historicamente, bem como das influências teóricas que a afetam e se fazem hegemônicas em um dado momento.

Utilizando a expressão "tradição inventada" de Goodson (1998) para referir-se ao currículo, Macedo (2013) afirma que esse objeto pode ser concebido como 
artefato socioeducacional que se configura nas ações de conceber/selecionar/produzir, organizar, institucionalizar, implementar/dinamizar saberes, conhecimentos, atividades, competências e valores visando uma 'dada' formação, configurada por processos e construções constituídos na relação com conhecimento eleito como educativo (grifos do autor) (MACEDO, 2013, p. 24-25)

Como o currículo é uma construção social, um dispositivo educacional atualiza-se de forma ideológica, política, ética, estética e cultural, configurando-se como um produto das relações e das dinâmicas interativas, instituindo, assim, poderes e orientando-se por determinados valores.

Nessa perspectiva, a configuração do currículo como conhecimento e valores orientados para uma determinada formação é explicitada nas palavras de Silva (2017),

O currículo é sempre o resultado de uma seleção: de um universo mais amplo de conhecimentos e saberes seleciona-se aquela parte que vai construir, precisamente, o currículo. As teorias do currículo, tendo decidido quais conhecimentos devem ser selecionados, buscar justificar por que esses conhecimentos e não aqueles devem ser selecionados (SILVA, 2017, p. 15)

Nesse sentido, cabe ao currículo escolar definir os saberes a serem transformados e recontextualizados para a escola como objetos de ensino. Não há, assim, uma definição melhor ou mais moderna de currículo, o que existe é a definição que melhor explicita a filosofia, os valores do grupo a que serve uma determinada proposta pedagógica. Um currículo ou uma proposta curricular, então, está sempre na dependência de um projeto de homem e de sociedade (MALTA, 2013).

Entendendo o currículo como o próprio fundamento de qualquer sistema de ensino, é relevante abordar como as concepções de língua(gem) aparecem nas teorias de currículo, a saber: tradicional, crítica e pós-crítica.

Sendo assim, o presente trabalho apresenta uma discussão acerca da relação (convergente e divergente) entre as teorias do currículo e as concepções de língua(gem) demonstrando como as diversas perspectivas de currículo influenciam o tratamento dado à língua(gem).

1.1 As concepções de língua como expressão do pensamento e instrumento de comunicação: currículo tradicional

Dado o seu caráter múltiplo, a linguagem tem sido estudada e definida sob diferentes abordagens (a linguagem como expressão do pensamento, a linguagem como instrumento de comunicação e a linguagem como forma de interação), que se caracterizam, basicamente, por priorizar ora um, ora outro dos aspectos que a constituem historicamente segundo as demandas de cada momento. Nessa mesma direção, Travaglia (1997) nos esclarece que a concepção de língua(gem) 
altera em muito o modo de estruturar o trabalho com a língua em termos de ensino. Como também, podemos considerar que o modo de se conceber a linguagem está ancorada em uma determinada visão curricular, pois é em nível do currículo que são estabelecidos os conhecimentos que merecem ser nele incluídos (SILVA, 2017).

A primeira concepção de língua está ligada ao conceito de expressão do pensamento e está relacionada ao ensino da gramática de língua latina, a poética e retórica de autores latinos. Nessa perspectiva, a língua é compreendida como homogênea, acabada, fechada e sem interferência do social, pois não considera que a produção de um enunciado, que se materializam em um gênero textual/discursivo, possui uma finalidade e utilização social. Isto é, "para essa concepção, o modo como o texto, que se usa em cada situação de interação comunicativa, não depende em nada de quem se fala, em que situação se fala, como, quando e para quem se fala" (TRAVAGLIA, 1997, p. 22). Em decorrência dessa concepção, os estudos tradicionais consideram apenas a variedade dita padrão ou culta, ignorando todas as outras formas de uso da língua, considerados desvios da língua pautada no modelo literário artístico. Soares (2002) sustenta que até a década de 1940 manteve-se a tradição da Gramática, Retórica e Poética, porque atendiam às exigências culturais da época da classe social privilegiada, camada que tinha acesso à escola.

A partir dos anos 60 do século XX, foi se tornando conhecida a segunda concepção de língua que é lembrada ainda hoje: a língua é um instrumento de comunicação, a língua é um código (conjunto de signos que se combinam segundo regras) que nos serve para a transmissão de informações. Para que a comunicação se efetive, esse código (com suas regras) deve ser dominado pelos falantes e utilizado de maneira convencionada e preestabelecida.

Partindo dessa concepção, o ensino de língua fundamentava-se na apropriação do código, cabendo ao professor garantir que o aluno conhecesse o sistema alfabético e a gramática, para que este pudesse utilizar o código, ora como emissor - codificador - ora como recebedor - decodificador, o que caracterizou o ensino de língua como sendo descritivo.

Ainda, segundo essa concepção, o sistema linguístico é acabado, no sentido da totalidade das formas fonéticas, gramaticais e lexicais da língua, garantindo a sua compreensão pelos locutores de uma comunidade. Privilegia-se, então, a forma, o aspecto material da língua, e as relações que constituem o seu sistema total, em detrimento do conteúdo, da significação e dos elementos extralinguísticos.

Importantes nomes fundamentaram os estudos da linguagem nessa concepção, como Saussure (fundador do Estruturalismo, no início deste século) e Chomsky (linguista americano que conduziu a gramática gerativo-transformacional). Conforme expõe Travaglia (1997, p. 22): 
Essa concepção levou ao estudo da língua enquanto código virtual, isolado de sua utilização - na fala (cf. Saussure) ou no desempenho (cf. Chomsky). Isso fez com que a Linguística não considerasse os interlocutores e a situação de uso como determinantes das unidades e regras que constituem a língua, isto é, afastou o indivíduo falante do processo de produção, do que é social e histórico na língua. Essa é uma visão monológica e imanente da língua, que a estuda segundo uma perspectiva formalista - que limita esse estudo ao funcionamento interno da língua - e que separa o homem no seu contexto social. (TRAVAGLIA, 1997, p. 22)

Sendo assim, a(s) concepção(ões) de língua(gem) ligadas ao conceito de expressão do pensamento e como instrumento de comunicação comungam com a teoria tradicional de currículo, uma vez que o conhecimento é concebido como algo estático e objetivo. Esse aspecto curricular preocupa-se com o modelo econômico em que vive a maioria dos países. Silva (2017) explica que essa teoria teve como principal representante Bobbit, que escreveu sobre o currículo em um momento no qual diversas forças políticas, econômicas e culturais procuravam envolver a educação de massas para garantir que sua ideologia fosse garantida. Sua proposta era que a escola funcionasse como uma empresa comercial ou industrial e que era necessário estabelecer padrões definitivos para os vários produtos educacionais.

Nesse sentido, o currículo em si atua de forma capitalista, como nos mostra Silva (2017):

\begin{abstract}
O currículo é capitalista. O currículo reproduz - culturalmente- as estruturas sociais. O currículo tem um papel decisivo na reprodução da estrutura de classes da sociedade capitalista. O currículo é um aparelho ideológico do Estado capitalista. O currículo transmite a ideologia dominante. O currículo é, em suma, um território político. (SILVA, 2017, p.148)
\end{abstract}

A razão desse enfoque é que os alunos visados pertencem à mesma camada social dominante. Com isso, o currículo tradicional atua como mecanismo de exclusão dos dominados.

O modelo curricular de Bobbitt iria encontrar sua consolidação definitiva num livro de Ralph Tyler, publicado em 1949. Suas ideias influenciaram diversos países, inclusive o Brasil. Tyler tinha uma visão formalista e neutra de currículo e acreditava que esse artefato era essencialmente técnico, centrado em como fazer o currículo.

Nesse sentido, a característica básica dessa teoria seria a ênfase em objetivos, estratégias, controle e avaliação.

No tocante à linguagem, Silva afirma que:

O currículo da escola está baseado na cultura dominante: ele se expressa na linguagem dominante, ele é transmitido através do código cultural dominante. As crianças das classes dominantes podem facilmente compreender esse código (...). Esse código é natural para elas (...). Em 
contraste, para as crianças e jovens das classes dominadas, esse código é simplesmente indecifrável (SILVA, 2017, p. 35)

Conforme a citação acima compreende-se que as concepções de língua como elemento de poder, de dominação e de exclusão é preponderante na teoria tradicional do currículo. Nesse sentido, o currículo é sempre um jogo de escolhas entre conhecimentos e saberes para obtenção de resultados esperados. Essa teoria pautava-se num modelo econômico e tinha como ideal a noção de eficiência e para isso, Bobbit baseava-se nos estudos de Frederick Taylor que apontavam para a administração científica. Assim, ele queria que

o sistema educacional fosse capaz de especificar precisamente que resultados pretendia obter, que pudesse estabelecer métodos para obtê-los de forma precisa e formas de mensuração que permitissem saber com precisão se eles foram realmente alcançados. (idem, p. 23)

Assim como afirmou Silva (2017), Bobbit permitia, em suas teorias, a cientificidade da educação, e isso se daria através de um mapeamento das habilidades necessárias à aprendizagem. Assim, o currículo deveria desenvolver as habilidades e planejar e elaborar instrumentos de medição para aferir se houve aprendizagem de maneira esperada, pois tratava-se de uma ação mecânica, burocrática e técnica.

Ao descrever as teorias tradicionais de currículo, autores como Silva (2017) e Marinho (2007) enfatizaram o caráter instrumental do processo de elaboração de currículo, moldando-se nos padrões econômicos de produção em massa, que se constituíam de teorias de ajuste, adaptação e aceitação, tomando o status quo como referência e "desconsiderando o caráter histórico e social do conhecimento, contribuindo para a reprodução de desigualdades sociais" (SILVA, 2017, p. 52).

\subsection{A concepção de língua como interação: currículo crítico e pós-crítico}

A linguagem como forma de ação ou processo de interação é vista como atividade discursiva humana e por intermédio dela os indivíduos praticam ações que envolvem tanto fala quanto escrita, considerando o contexto sócio-histórico e ideológico que estão envolvidos no ato comunicativo. Ou seja, para essa concepção a língua é encarada como um conjunto de práticas sociais e de linguagem historicamente situadas, em diversas esferas de comunicação da atividade humana, como propõe Bakhtin:

todas as esferas da atividade humana, por mais variadas que sejam, estão sempre relacionadas com a utilização da língua. Não é de surpreender que o caráter e os modos dessa utilização sejam tão variados como as próprias 
esferas da atividade humana, o que não contradiz a unidade nacional de uma língua. (BAKHTIN, 1986, p. 04).

Alinhando-se a essa concepção, Travaglia (1997, p. 23) afirma que o indivíduo faz ao usar a língua não é tão-somente traduzir e exteriorizar um pensamento ou transmitir informações a outrem, mas sim realizar ações, agir, atuar sobre o interlocutor (ouvinte/leitor). Ao contrário das concepções anteriores, esta concepção situa a linguagem como um lugar de interação humana, como o lugar de constituição de relações sociais que colocam no centro da reflexão o sujeito da linguagem, as condições de produção do discurso, o social, as relações de sentido estabelecidas entre os interlocutores, a dialogia, a argumentação, a intenção, a ideologia, a historicidade da linguagem etc.

Desse modo, esta concepção vem alterar o cerne do ensino de língua, pois é a partir daí que a linguagem é vista como processo de interação, considerando-se os diferentes sentidos que ela assume em diferentes situações sociocomunicativas. Converge para essa concepção de língua a teoria crítica e pós-crítica de currículo.

A teoria crítica é baseada nas estruturas políticas e econômicas e na reprodução cultural e social, surgindo a partir das críticas inspiradas em estratégias interpretativas de investigação, como a fenomenologia e a hermenêutica que consideram que as categorias (de aprendizagem, objetivos, medição e avaliação) deveriam ser questionadas para chegar à essência da educação e do currículo. Além disso, as teorias críticas entendem a educação como resultante de um arranjo social e denuncia o processo de homogeneização veiculado pelo currículo, em favor de grupos hegemônicos e suas cosmovisões (MACEDO, 2013).

A linguagem, então, passa por uma reconceptualização que, segundo Giroux (1993, p. 58) é caracterizada pela redefinição da "natureza da linguagem como um sistema de signos estruturados no jogo infinito da diferença", com o enfraquecimento da "noção dominante, positivista da linguagem, seja como um código genético estruturado de forma permanente, seja simplesmente como meio linguístico, transparente para transmitir ideias e significados".

Nesse momento, verifica-se uma primeira influência de Paulo Freire no pensamento curricular, na década de 1970. Conforme Moreira (2010), Freire preocupa-se com uma educação consciente, libertadora dos oprimidos, possibilitando-Ihes uma reflexão crítica sobre o seu papel de vencer as injustiças sociais. Para que essa educação libertadora aconteça, um novo currículo faz-se necessário, uma vez que o currículo tradicional é desvinculado da vida social, é neutro e não favorece o desenvolvimento da consciência crítica do educando.

$\mathrm{Na}$ teoria crítica curricular de Freire podemos inserir a concepção interacionista da linguagem, uma vez que ele utiliza as experiências de seus alunos para determinar os conteúdos programáticos, tornando, assim, o conhecimento significativo para quem aprende. No entanto, não nega o papel dos 
especialistas para organizar os temas de forma interdisciplinar. Os conteúdos são definidos junto com os educandos e na realidade em que estão situados. Ele elimina a diferença entre cultura popular e cultura erudita e permite que a primeira também seja considerada conhecimento que legitimamente faz parte do currículo.

Já as teorias pós-críticas de currículo se pautam, sobretudo, nas relações de multiculturalidade, identidade e poder. É desse ponto de vista que o currículo abarca as diferenças que compõem a sociedade e as consideram um processo linguístico e discursivo, defendendo que a diferença é "discursivamente produzida", assim como "na mesma medida em que é uma relação social, o processo de significação que produz a 'diferença' se dá em conexão com relações de poder" (SILVA, 2017, p. 87).

É dentro dessas teorias que o olhar para os sujeitos e suas constituições identitárias se intensifica, e elementos como raça, gênero e sexualidade passam a ter forte influência na constituição dos currículos escolares. É um momento de despertar na escola o olhar crítico para os sujeitos que a compõem. No ensino de língua portuguesa, por sua vez, o currículo aproxima-se da concepção de língua enquanto interação e ferramenta de atuação social, de modo que não mais se baseia na construção de textos e ensino conteúdos desconexos de sua função social e política. O currículo abrange a multiculturalidade e torna a escola um espaço mais democrático e mais justo na formação cidadã. (MARCUSCHI, 2008; CORREA, 2003).

Desta forma, a análise do discurso, a sociolinguística, o sociointeracionismo e outras teorias passam a ser contempladas dentro do currículo para o ensino de língua de maneira interdisciplinar, correlacionadas a fatores sociais, históricos e culturais. A análise do discurso, por exemplo, tem grande força ao discorrer sob uma perspectiva linguística que considera o sujeito em interação, de maneira que "põe em cena a questão de que não se pode reduzir o linguístico nem ao social, nem ao psicológico, pois a linguagem é, ao lado de integralmente linguística, integralmente histórica" (MARCUSCHI, 2008, p. 42). Desta feita, o currículo pautado em teorias interacionistas considera a história dos sujeitos que fazem parte do ambiente escolar. Baptista (2012), ao discorrer sobre o letramento crítico, afirma que nessa teoria é necessário

\footnotetext{
o tratamento ético dos discursos na sociedade, a contextualização dos significados e a mobilização dos sujeitos para fazerem escolas [...] com esse propósito o letramento crítico procura o engajamento do aluno em uma atividade reflexiva por meio da linguagem, valendo-se para tanto do questionamento das relações de poder e das implicações destas para a vida do sujeito ou de sua comunidade (BAPTISTA, 2012, p. 146-147)
}

É esse engajamento social e crítico que reflete os ideais das teorias pós-críticas do currículo e por meio de uma perspectiva multicultural busca as relações de poder entre grupos dominantes e 
minorias objetivando uma maior igualdade e respeito mútuos entre diferentes grupos sociais, não transmitindo em ambientes escolares apenas a cultura dominante ou a tradição e sim todas as manifestações culturais que compõem a sociedade (SILVA, 2017).

Macedo (2007) defende que embora os professores tenham a sua prática intrinsecamente relacionadas aos âmbitos curriculares, há hoje certa inquietação quando referente à compreensão da ideia de currículo apresentada pelos docentes. Para ele os profissionais da Educação compreendem aplicabilidade política cultural e ideológica do currículo, no entanto não conseguem defini-lo realmente. Nas palavras do autor, "há uma perplexidade demonstrada pelos professores, por exemplo, ao se convencerem de que não sabem nocionar o currículo, tampouco discutir suas implicações, mesmo se reconhecendo atores constitutivos desse importante artefato educacional. " (MACEDO, 2013, p. 29)

Moreira (2012) acredita que o lugar de destaque concedido aos estudos no campo de currículo no conhecimento pedagógico ocorre em virtude da importância significativa de sua aplicabilidade em diferentes sociedades, tanto no que concerne a conservação ou renovação dos conhecimentos historicamente acumulados, quanto para propagação de valores desejáveis. Para ele, é necessário que se considere as abordagens que se voltam para o currículo escolar, como o formal, o real e o oculto, assim, considerando as prescrições, o que realmente ocorre em sala de aula e o aprendizado que se constitui além no ambiente escolar. $O$ autor ainda afirma que essa nova visão de currículo

\footnotetext{
Aponta, assim, para o fato de que no currículo desenvolvem-se representações, codificadas de forma complexa nos documentos, a partir de interesses, disputas e alianças, e de codificadas nas escolas, também de modo complexo, pelos indivíduos nelas presentes. Sugere, ainda, a visão do currículo como um campo de lutas e conflitos em torno de símbolos e significados" (MOREIRA, 2012, p. 15)
}

Sobre isto, Macedo (2013) afirma que a concepção formalista de currículo, que Silva (2017) denomina tradicional é reconfigurada por meio das teorias críticas e pós críticas, assim, passase a buscar compreender o que o currículo faz com as pessoas e instituições, e não apenas o fazer do currículo. A teoria pós crítica considera que somos seres subjetivos, e que construímos o nosso conhecimento de forma intersubjetiva, e desta forma "que o currículo se configura como um produto das relações e das dinâmicas interativas, vivo e Instituto" (MACEDO, 2013, p. 25).

A relevância social da linguagem é explicitada a partir dos anos 90 quando o ensino de língua incorpora teorias da linguística da enunciação e teóricos como Michael Bakhtin apresenta a língua como dispositivo de inserção social, quando considera "os conceitos de gênero, de condições de produção do discurso, da linguagem como sócio interação, como arena de lutas ideológicas" 
(GREGOLIN, 2007, p. 69). Nessa perspectiva, a significação tem real importância na construção das relações sociais, tendo em vista que "luta por significado é luta por recursos de poder" (MACEDO, 2013, p. 28).

Discorrendo sobre a sociedade enquanto espaço ideológico, Dunker (2008) afirma que um discurso torna-se ideológico quando articulado com as dimensões de espaço, lugar e posição, de forma que esse espaço ideológico seja "a suposição necessária da infinitude dos discursos, ou de 'tudo pode ser dito' porque o espaço onde se vive, fala e trabalha é afinal um único, homogêneo e transparente" (DUNKER, 2008, p. 197), por mais que isso se constitua uma fantasia ideológica lógica, já que esses discursos estão distribuídos em espaços heterogêneos compreendidos entre diferentes níveis do saber.

Importantes considerações sobre o currículo e a linguística são apresentadas por Marinho (2007). Ao discorrer sobre as perspectivas de análise de currículos, a autora defende que é relevante assumir uma perspectiva discursiva, considerando que a linguagem é resultado do trabalho e da interação entre os sujeitos, e essa relação deve ser analisada dentro de um contexto sociocultural já que existem fortes relações entre currículo e as relações de poder. Para ela, com os avanços nas relações sobre currículo, foi necessário vislumbrar a linguagem como fenômeno heterogêneo, advinda de diferentes sujeitos inseridos nas mais diversas condições sociais, históricas e culturais. Assim se tornava necessária uma redefinição dos paradigmas de linguagem, língua e ensino-aprendizagem. Essa inovação significava " aderir a pressupostos advindos das teorias da enunciação, da análise do discurso, da pragmática, da psicolinguística, da linguística textual, da sociolinguística, do sociointeracionismo, do construtivismo, entre outros" (MARINHO, 2007, p. 185).

O ensino de língua, de acordo com Gregolin (2007), passou por uma crise teórica e consequentemente por mudanças, assim, a ampliação do ensino público no Brasil, quando passou a atender às mais variadas classes econômicas, como um momento de abertura para a diversidade das experiências linguísticas na sala de aula. Para ela, é interessante ler os documentos oficiais que já nortearam o ensino de língua no nosso país para que se possa perceber a tensão que se instaurou entre a gramática normativa e a linguística e que agora se torna uma relação de complementaridade. Tais mudanças ocorrem a partir dos dobramentos teóricos que se dão nos estudos linguísticos, ocasionando uma mudança no foco do ensino de língua, de forma que

o texto curricular se transforma em um exercício de argumentação intensa sobre a mudança de foco de uma perspectiva considerada a tradicional- preferencialmente orientada pelo ensino gramatical, por uma concepção estruturalista da língua- para uma perspectiva considerada inovadora- orientada pelo texto, pelo discurso, numa perspectiva enunciativa da linguagem. (MARINHO, 2007, p. 189) 
Sobre essa perspectiva inovadora no ensino da língua, Correia (2002), ao discorrer sobre a locução e sobre a produção de enunciados, evidencia a presença de um sujeito considerando-o essencial para a produção de sentido, enquanto Morato (2004, p. 317) afirma que esse "sujeito é interpelado e reconhecido socialmente por meio dos outros, por meio do discurso dos outros, por meio de discursos outros que constituem o seu próprio discurso. ". Logo, reconhece-se que a língua "não é só signo, é ação, é trabalho coletivo dos falantes, não é simplesmente um intermediário entre o nosso pensamento e o mundo" (idem). Ainda de acordo com a autora, essas relações são mobilizadas com relação a vários fatores além da apropriação do sistema linguístico entre eles propriedades biológicas e psíquicas qualidade das interações que mantemos em sociedade valor intersubjetivo da linguagem e as contingências materiais da vida, além dos universos discursivos a qual fazemos parte. Ela ainda destaca que a relação entre linguagem e processos cognitivos corroborou para estudos no campo do interacionismo principalmente após os anos 60 assim superando a noção de língua como expressão do pensamento instrumento de comunicação e correlacionando com as interações sociais, dando subsídio necessário para os atuais estudos em linguística. Para ela,

\begin{abstract}
A língua não é um instrumento: ou seja, a língua não é uma espécie de ferramenta que os falantes utilizam para certos fins (comunicacionais, por exemplo) [...] aceitar que seja um instrumento significaria tomar a língua como algo completamente exterior ao sujeito. [...] tampouco a língua é expressão do pensamento [...] porque essa concepção leva a aceitar que pode haver pensamento (conceitos, ideias, etc) sem linguagem, ou, antes dela, cuja origem fosse a mente do sujeito. (MORATO, 2004, p. 361)
\end{abstract}

Desta feita, essa visão de língua enquanto produto de relações sociais, bem como a teoria póscrítica de currículo, evidenciam a necessidade de considerar as dimensões interativas e heterogêneas da linguagem, como também, a necessidade de ancorar tais estudos em um paradigma que abarque a complexidade de tais relações, apontando para o que afirmara Gregolin (2007): "Essa posição aponta que estamos em vias de observar uma virada paradigmática nos estudos da linguagem, uma virada política linguística, [...] a língua entra a serviço de um poder" (GREGOLIN, 2007, p. 91-92).

\title{
Considerações finais
}

Ao final, é perceptível que o ensino de língua materna no Brasil foi fortemente influenciado pelas teorias de currículo que perpassaram o ambiente de ensino aprendizagem, assim como são evidentes as mudanças pelas quais passou o ensino de língua portuguesa ao longo dos anos. Os estudos de currículo permitiram maior flexibilidade e respeito às diferenças dentro do ambiente escolar, assim podemos inferir que o ensino de língua materna foi influenciado por essas teorias. 
Tanto as concepções de língua, quanto as teorias de currículo foram influenciadas pela pesquisa de sua época. $O$ currículo que antes percebia o ambiente escolar sob os moldes de uma fábrica, seguido objetivos pré-estabelecidos para obtenção de resultados, baseado numa lógica mercadológica, passa a contemplar as diferenças que compõem as mais diversas sociedades e sujeitos, conferindo-Ihes autonomia, poder e identidade por meio da formação escolar. No âmbito linguístico, parte-se de um ensino tradicional, pautado em modelos literários e ensino da retórica, para o ensino que confere ao aluno poder por meio de seus discursos e práticas em sociedade.

Por fim, é relevante salientar que a concepção de língua enquanto interação social, aliada às teorias pós-críticas de currículo, promoveram melhorias ao ensino de língua portuguesa no Brasil, permitindo-Ihes uma formação mais completa em relação ao uso da sua língua materna e sua posição na vida em sociedade, sendo possível a mobilização de conhecimentos a fim de promover uma ação social efetiva por meio da interação entre os sujeitos.

\section{CURRICULAR THEORIES AND LANGUAGE CONCEPTIONS IN PORTUGUESE LANGUAGE TEACHING}

Abstract: The studies of curriculum pass through all the entire education sphere and directly influence the teaching and the learning in all levels of education and formation. It's through this context that we performed the bibliographic review that follows, to identify the relations between the traditional, critical and post-critical theories of curriculum and the conceptions of language that guided and still guide the teaching of Portuguese as a native language. We take as a base the historical course traced by Marinho (2007), Macedo (2013) and Moreira (1999; 2010; 2012) e Silva (2017)about the curriculum studies, correlating it to the conceptions of language presented by several authors: Morato (2004), Correa (2003), Marcuschi (2008), and others.

Keywords: Curriculum theories; language conceptions; portuguese language teaching.

\section{Referências}

BAKHTIN, M. Marxismo e filosofia da linguagem. São Paulo: Hucitec, 1986.

BAPTISTA, L. M. T. R.. Letramento crítico, discursos e ideologia. In: MILREU, I. RODRIGUES, M. C. Ensino de língua e literatura: políticas, práticas e projetos. Campina Grande: Bagagem/UFCG, 2012.

CHERRYHOLMES, C. H. Um projeto social para o currículo: perspectivas pós-estruturais. IN: SILVA, T. T. (org). Teoria educacional crítica em tempos pós-modernos. Porto Alegre: Artes Médicas, 1993, p. 143172.

CORAZZA, S. M. O que quer um currículo: pesquisas pós-críticas em educação. Petrópolis: Vozes, 2001. CORREA, M. L. G. Linguagem e comunicação: visões da linguística moderna. São Paulo: Parábola Editorial, 2003.

DUNKER, C. I. L. Discurso e ideologia. In: SIGNORINI, Inês. [Re]Discutir texto, gênero e discurso. São Paulo: Parábola Editorial, 2008.

FREIRE, P. Pedagogia do oprimido. 35. ed. Rio de Janeiro: Paz e Terra, 2003.

GIROUX, H A. O pós-modernismo e o discurso da crítica educacional. IN: SILVA, T. T. (org). Teoria educacional crítica em tempos pós-modernos. Porto Alegre: Artes Médicas, 1993, p. 41-69. 
GREGOLIN, M. R. Comunicação, mídia e consumo: análise do discurso e mídia: a (re)produção de identidades. São Paulo, Vol. 4, N. 11, P. 11-25 Nov. 2007.

KOCH, I. G. V. A inter-ação pela linguagem. São Paulo: Contexto, 1992.

ALB, 1996.

Linguagem e ensino: exercícios de militância e divulgação. Campinas, SP: Mercado de Letras-

MACEDO, R. S.. Currículo: campo, conceito e pesquisa. 6 ed. Petrópolis: Vozes, 2013.

MALTA, S. C. L. Uma abordagem sobre currículo e teorias afins visando à compreensão e mudança. Espaço do currículo, v.6, n.2, p.340-354, maio a agosto de 2013.

MARCUSCHI, L. A. Produção textual, análise de gêneros e compreensão. São Paulo: Parábola Editorial, 2008.

MARINHO, M. Currículos contemporâneos: novos conteúdos, nova retórica? In: MATTE, A. C. F. Lingua(gem), texto, discurso: entre a reflexão e a prática. Rio de Janeiro: Lucerna, 2007.

MOITA LOPES, L. P. (Org.) Discursos de identidades: discurso como espaço de construção de gênero, sexualidade, raça, idade e profissão na escola e na família. Campinas, SP: Mercado das Letras, 2003.

MORATO, L. O interacionismo no campo linguístico. IN: MUSSALIN, F. e BEBTES, A. C. Introdução à Linguística: fundamentos epistemológicos. São Paulo: Cortez, 2004.

MOREIRA, A.F.B. Currículos e programas no Brasil. 4 ed. Campinas: Papirus, 1999.

Antônio Flávio Barbosa Moreira, pesquisador de currículo. Belo Horizonte: Autêntica, 2010. Currículo: Questões atuais. 18 ed. São Paulo: Papirus, 2012.

MUSSALIM, F. BENTES, A. C.. Introdução à linguística: Fundamentos epistemológicos. Vol 3. 3 ed. São Paulo: Cortez, 2007.

SILVA, T. T. Documentos de identidade: uma introdução às teorias do currículo. 3 a edição. Belo Horizonte: Autêntica, 2017.

SOARES, M. B. Linguagem e escola: uma perspectiva social. São Paulo: Ática, 2002.

TRAVAGLIA, L. C. Gramática e Interação: uma proposta para o ensino de gramática no 1 e 2 graus. São Paulo: Cortez, 1997.

VEIGA, I. P. A. C, M. H. Escola Fundamental, currículo e ensino. 2 ed. Campinas: Papirus, 1995. 